\title{
Urinary angiotensinogen is a marker for tubular injuries in patients with type 2 diabetes
}

This article was published in the following Dove Press journal: International Journal of Nephrology and Renovascular Disease 21 October 2013

Number of times this article has been viewed

\author{
Takahiro Terami' \\ Jun Wada' \\ Kentaro Inoue ${ }^{\prime}$ \\ Atsuko Nakatsuka ${ }^{1,2}$ \\ Daisuke Ogawa ${ }^{1,2}$ \\ Sanae Teshigawara' \\ Kazutoshi Murakami ${ }^{1,3}$ \\ Akihiro Katayama' \\ Jun Eguchi' \\ Hirofumi Makino' \\ 'Department of Medicine and Clinical \\ Science, ${ }^{2}$ Department of Diabetic \\ Nephropathy, ${ }^{3}$ Department of General \\ Medicine, Okayama University \\ Graduate School of Medicine, \\ Dentistry and Pharmaceutical \\ Sciences, Okayama, Japan
}

Correspondence: Jun Wada Department of Medicine and Clinical Science, Okayama University Graduate School of Medicine, Dentistry and Pharmaceutical Sciences, 2-5-I Shikatacho, Kita-ku, Okayama 700-8558, Japan $\mathrm{Tel}+81862357235$

Fax +81862225214

Email junwada@md.okayama-u.ac.jp
Purpose: Urinary angiotensinogen has been reported as a marker for the activation of intrarenal renin-angiotensin system (RAS) in various kidney diseases. To investigate the importance of urinary angiotensinogen in diabetic nephropathy, we compared the urinary levels of angiotensinogen, albumin, and $\alpha 1-$ microglobulin.

Materials and methods: Japanese patients with type 2 diabetes at various stages of nephropathy $(n=85)$ were enrolled, and we measured albumin/creatinine ratio (ACR) and urinary excretion of angiotensinogen and $\alpha 1$-microglobulin. We also compared the clinical data of the patients treated with or without angiotensin II receptor blockers or angiotensin-converting enzyme inhibitors (RAS inhibitors [+], $\mathrm{n}=51$; RAS inhibitors [-], n=34).

Results: Urinary angiotensinogen levels positively correlated with ACR $\left(r=0.367, P=3.84 \times 10^{-4}\right)$ and urinary $\alpha 1$-microglobulin $\left(r=0.734, P=1.32 \times 10^{-15}\right)$, while they negatively correlated with estimated glomerular filtration ratio (eGFR) $\left(r=-0.350, P=1.02 \times 10^{-3}\right)$ and high-density lipoprotein cholesterol $(r=-0.216, P=0.049)$. Multiple regression analysis was carried out to predict urinary angiotensinogen levels by employing eGFR, ACR, and urinary $\alpha 1$-microglobulin as independent variables; only urinary $\alpha 1$-microglobulin entered the regression equation at a significant level. Although ACR was higher in the RAS inhibitors (+) group, urinary $\alpha 1$-microglobulin and angiotensinogen did not show significant increase in the RAS inhibitors (+) group.

Conclusion: Urinary angiotensinogen is well correlated with urinary $\alpha 1$-microglobulin and reflected the tubular injuries which may be associated with the intrarenal RAS activation in patients with type 2 diabetes.

Keywords: diabetic nephropathy, urinary biomarkers, renin-angiotensin system, angiotensinogen, $\alpha 1$-microglobulin, albumin

\section{Introduction}

The role of local renin-angiotensin system (RAS) in kidney tissues in the pathophysiology of diabetic nephropathy has been emphasized. ${ }^{1}$ The hyporeninemic hypoaldosteronism observed along with the progression of diabetic nephropathy and the efficacy of RAS inhibitors reducing the albuminuria in such patients also supports the notion that intrarenal RAS plays an important role in the progression of diabetic nephropathy. Sawaguchi et $\mathrm{al}^{2}$ reported that the baseline urinary excretion of angiotensinogen $(10-150 \mu \mathrm{g} / \mathrm{gCr})$ positively correlated with albumin/creatinine ratio $(r=0.77, P<0.001)$ and urinary $\beta 2$-microglobulin $(r=0.72, P<0.001)$ in type 2 diabetes patients with normo- and microalbuminuria. Furthermore, urinary angiotensinogen significantly correlated with annual decline of estimated glomerular filtration rate (eGFR) $(r=-0.51$, $P<0.001$ ), and a higher level of urinary angiotensinogen is a risk for the progression of 
diabetic nephropathy. ${ }^{2}$ Most of the clinical studies measuring urinary angiotensinogen and albumin levels demonstrated the strong correlation between two proteins with comparable molecular weight (67 and $65 \mathrm{kDa}$ ). Thus, it is still unknown whether urinary angiotensinogen is a marker of impairment of glomerular permeability like albumin/creatinine ratio (ACR), a marker of tubular interstitial injuries or a biomarker for the activation of intrarenal RAS in diabetic nephropathy. In this study, we measured ACR, urinary $\alpha 1$-microglobulin, and urinary angiotensinogen levels in patients with various stages of diabetic nephropathy and investigated the clinical significance of urinary angiotensinogen in diabetic nephropathy.

\section{Materials and methods}

\section{Patients}

We recruited Japanese patients with type 2 diabetes $(n=85$, $62.9 \pm 11.3$ years) into this study at Okayama University Hospital. The current study is a substudy of the report and shared the recruited patients. ${ }^{3}$ Patients were treated with oral hypoglycemic agents $(n=48)$ and insulin $(n=49)$. The patients with hypertension $(n=59)$ were treated with angiotensin II receptor blockers ( $A R B ; n=49)$, angiotensin-converting enzyme inhibitors (ACEI; $n=13$ ), calcium channel blockers $(n=34)$, and diuretics $(n=11)$. We compared the clinical data of the patients treated with ARB or ACEI (RAS inhibitors [+]; $\mathrm{n}=51$ ) without ARB and ACEI (RAS inhibitors [-]; $\mathrm{n}=34$ ). Dyslipidemia was noted in 53 patients; most of these patients were treated with statins $(n=45)$. The patients with eGFR $<15 \mathrm{~mL} / \mathrm{min} / 1.73 \mathrm{~m}^{2}$ or those undergoing dialysis were excluded from the current study. All recruited patients with type 2 diabetes agreed to measure urinary levels of $\alpha 1-$ microglobulin and angiotensinogen. The study was conducted in accordance with the ethical principle of the Declaration of Helsinki and was approved by the ethical committee of Okayama University Graduate School of Medicine, Dentistry, and Pharmaceutical Sciences. Written informed consent was obtained from each patient.

\section{Blood sampling and assays}

We measured overnight fasting serum levels of total cholesterol and low-density lipoprotein (LDL) cholesterol, high-density lipoprotein (HDL) cholesterol, triglycerides (Wako L Type Triglyceride H; Wako Pure Chemical Industries, Osaka, Japan), uric acid, creatinine $(\mathrm{Cr})$, and urea nitrogen. $\mathrm{HbA}_{1 \mathrm{c}}$ levels were also measured. Urinary albumin was measured in random spot urine samples by standard immunonephelometric assay. The urinary ACR was calculated. eGFR was calculated by the equation

$$
\text { eGFR }\left(\mathrm{mL} / \mathrm{min} / 1.73 \mathrm{~m}^{2}\right)=194 \times \mathrm{Cr}^{-1.094} \times \mathrm{age}^{-0.287}
$$

in males and

eGFR $\left(\mathrm{mL} / \mathrm{min} / 1.73 \mathrm{~m}^{2}\right)=194 \times \mathrm{Cr}^{-1.094} \times \mathrm{age}^{-0.287} \times 0.739$

in females. Urinary excretions of $\alpha 1$-microglobulin and angiotensinogen were measured with enzyme-linked immunosorbent assay (ELISA) kits; LZ Test Eiken $\alpha 1-\mathrm{M}$ (Eiken Chemical Co, Tokyo, Japan), and Human Total Angiotensinogen Assay Kit (Immuno-Biological Laboratories Co, Ltd, Fujioka, Gunma, Japan).

\section{Statistical analysis}

All data are expressed as mean \pm standard deviation values. Spearman correlation coefficients were used to evaluate whether urinary levels of angiotensinogen correlated with various parameters. To determine the variables independently associated with urinary levels of angiotensinogen in the patients with type 2 diabetes, multiple regression analysis was performed by including eGFR, ACR, and urinary $\alpha 1-$ microglobulin/creatinine ratio as independent variables. Urinary levels of $\alpha 1$-microglobulin, angiotensinogen, and various clinical parameters in RAS inhibitors (-) and RAS inhibitors $(+)$ groups were compared by Mann-Whitney $U$ testing. $P$-values less than 0.05 were considered statistically significant. Statistical analysis was performed with IBM SPSS Statistics Base and IBM SPSS Regression (IBM Corporation, Armonk, NY, USA).

\section{Results \\ Correlation of urinary angiotensinogen with urinary $\alpha \mathrm{I}$-microglobulin}

The type 2 diabetes patients $(n=85)$ with various albuminuria stages (ie, normo $[n=36]$, micro- $[n=25]$, and macroalbuminuric $[\mathrm{n}=24]$ stages) were recruited into the study and were classified into RAS inhibitors (-) and RAS inhibitors (+) groups (Table 1). At each albuminuria stage, we observed significantly different serum concentrations of total protein (demonstrated by Kruskal-Wallis test) $(70.4 \pm 4.3 \mathrm{~g} / \mathrm{L}$, $70.7 \pm 4.8 \mathrm{~g} / \mathrm{L}, 66.1 \pm 6.5 \mathrm{~g} / \mathrm{L} ; P=0.003)$, albumin $\left(42.9 \pm 2.5 \mathrm{~g} / \mathrm{L}, 41.2 \pm 3.2 \mathrm{~g} / \mathrm{L}, 35.7 \pm 7.0 \mathrm{~g} / \mathrm{L} ; P=1.80 \times 10^{-16}\right)$, creatinine $(66.4 \pm 13.3 \mu \mathrm{mol} / \mathrm{L}, 78.3 \pm 26.3 \mu \mathrm{mol} / \mathrm{L}$, $\left.144.2 \pm 70.3 \mu \mathrm{mol} / \mathrm{L} ; P=4.86 \times 10^{-10}\right)$, urea nitrogen $(5.5 \pm 1.5 \mu \mathrm{mol} / \mathrm{L}, 7.1 \pm 2.7 \mu \mathrm{mol} / \mathrm{L}, 10.0 \pm 3.8 \mu \mathrm{mol} / \mathrm{L}$; $\left.P=5.92 \times 10^{-8}\right)$, uric acid $(305.8 \pm 61.5 \mu \mathrm{mol} / \mathrm{L}$, $352.8 \pm 96.2 \mu \mathrm{mol} / \mathrm{L}, 396.2 \pm 68.0 \mu \mathrm{mol} / \mathrm{L} ; P=9.68 \times 10^{-5}$ ), 
Table I Comparison of various parameters in the type 2 diabetes patients $(n=85)$ with normo- $(n=36)$, micro- $(n=25)$, and macroalbuminuric $(n=24)$ stages

\begin{tabular}{|c|c|c|c|c|}
\hline & RAS inhibitors (-) & RAS inhibitors (+) & Total & Mann-Whitney U \\
\hline Number (male/female) & $34(16 / 18)$ & $5 I(33 / / 8)$ & $85(49 / 36)$ & \\
\hline Age (years $\pm S D$ ) & $63.1 \pm 11.7$ & $62.5 \pm 11.1$ & $62.9 \pm 11.3$ & 0.492 \\
\hline $\mathrm{BMI}\left(\mathrm{kg} / \mathrm{m}^{2} \pm \mathrm{SD}\right)$ & $24.5 \pm 4.4$ & $25.1 \pm 4.7$ & $24.9 \pm 4.6$ & 0.618 \\
\hline $\mathrm{SBP}(\mathrm{mmHg} \pm \mathrm{SD})$ & $122.9 \pm 13.4$ & $128.3 \pm 19.2$ & $126.2 \pm 17.3$ & 0.216 \\
\hline $\mathrm{DBP}(\mathrm{mmHg} \pm \mathrm{SD})$ & $71.2 \pm 10.9$ & $72.8 \pm 11.2$ & $72.2 \pm 11.1$ & 0.339 \\
\hline $\mathrm{HbA}_{\mathrm{Ic}}(\% \pm \mathrm{SD})$ & $7.27 \pm 0.68$ & $7.33 \pm 0.98$ & $7.31 \pm 0.87$ & 0.974 \\
\hline Total protein $(g / L \pm S D)$ & $70.1 \pm 5.8$ & $68.7 \pm 5.1$ & $69.3 \pm 5.4$ & 0.339 \\
\hline Albumin $(g / L \pm S D)$ & $41.4 \pm 5.8$ & $39.6 \pm 5.0$ & $40.4 \pm 5.3$ & $0.032 *$ \\
\hline $\mathrm{Cr}(\mu \mathrm{mol} / \mathrm{L} \pm \mathrm{SD})$ & $81.4 \pm 53.9$ & $98.8 \pm 50.6$ & $91.9 \pm 52.3$ & $0.028^{*}$ \\
\hline UN $(\mu \mathrm{mol} / \mathrm{L} \pm \mathrm{SD})$ & $7.0 \pm 3.4$ & $7.4 \pm 3.2$ & $7.3 \pm 3.3$ & 0.418 \\
\hline Uric acid $(\mu \mathrm{mol} / \mathrm{L} \pm \mathrm{SD})$ & $321.3 \pm 66.8$ & $360.3 \pm 89.8$ & $344.6 \pm 83.1$ & $0.034^{*}$ \\
\hline T-Cho (mmol/L \pm SD) & $5.32 \pm 1.01$ & $4.77 \pm 0.88$ & $4.99 \pm 0.97$ & $0.011 *$ \\
\hline $\mathrm{TG}(\mathrm{mmol} / \mathrm{L} \pm \mathrm{SD})$ & $1.76 \pm 1.07$ & $1.84 \pm 1.37$ & $1.81 \pm 1.26$ & 0.904 \\
\hline $\mathrm{HDL}-\mathrm{C}(\mathrm{mmol} / \mathrm{L} \pm \mathrm{SD})$ & $1.51 \pm 0.45$ & $1.29 \pm 0.31$ & $1.38 \pm 0.39$ & $0.04 I^{*}$ \\
\hline LDL-C (mmol/L $\pm \mathrm{SD})$ & $3.03 \pm 0.84$ & $2.62 \pm 0.74$ & $2.79 \pm 0.80$ & 0.024 \\
\hline eGFR $(\mathrm{mL} / \mathrm{min} \pm \mathrm{SD})$ & $68.5 \pm 20.7$ & $60.2 \pm 23.0$ & $63.5 \pm 22.4$ & 0.052 \\
\hline $\mathrm{ACR}(\mathrm{mg} / \mathrm{gCr} \pm \mathrm{SD})$ & $368.2 \pm 863.8$ & $489.8 \pm 779.8$ & $441.2 \pm 812$ & $0.006 * *$ \\
\hline$\alpha \mathrm{I}$-microglobulin $(\mu g / g C r \pm S D)$ & $7.26 \pm 13.2$ & $9.63 \pm 10.6$ & $8.68 \pm 11.74$ & 0.306 \\
\hline Angiotensinogen $(\mu \mathrm{g} / \mathrm{gCr} \pm \mathrm{SD})$ & $13.3 \pm 27.5$ & $34.6 \pm 71.5$ & $26.1 \pm 58.8$ & 0.374 \\
\hline
\end{tabular}

Notes: The patients are classified whether they are treated with or without angiotensin receptor blockers or angiotensin-converting enzyme inhibitors. $* P<0.05$; $* * P<0.01$.

Abbreviations: ACR, albumin/creatinine ratio; BMI, body mass index; $\mathrm{Cr}$, serum creatinine; DPB, diastolic blood pressure; eGFR, estimated glomerular filtration ratio; $\mathrm{HbA}_{1 \mathrm{c}}$, hemoglobin $\mathrm{A}_{1 \mathrm{c}}$; HDL-C, HDL cholesterol; LDL-C, LDL cholesterol; RAS inhibitors (+), patients treated with angiotensin II receptor blockers or angiotensinconverting enzyme inhibitors; RAS inhibitors (-), patients not treated with angiotensin II receptor blockers or angiotensin-converting enzyme inhibitors; SD, standard deviation; SBP, systolic blood pressure; T-Cho, total cholesterol; TG, triglyceride; UN, serum urea nitrogen.

HDL-C $(1.49 \pm 0.41 \mathrm{mmol} / \mathrm{L}, 1.35 \pm 0.31 \mathrm{mmol} / \mathrm{L}$ $1.23 \pm 0.39 \mathrm{mmol} / \mathrm{L} ; P=0.031)$, and eGFR $(74.5 \pm 16.3 \mathrm{~mL} / \mathrm{min}$, $\left.67.9 \pm 19.2 \mathrm{~mL} / \mathrm{min}, 42.4 \pm 19.0 \mathrm{~mL} / \mathrm{min} ; P=6.66 \times 10^{-9}\right)$. Urinary proteins also significantly increased with the progression of albuminuria stages: ACR $(12.7 \pm 6.0 \mathrm{mg} / \mathrm{gCr}$, $\left.114.3 \pm 72.6 \mathrm{mg} / \mathrm{gCr}, 1.424 \pm 996 \mathrm{mg} / \mathrm{gCr} ; P=1.81 \times 10^{-16}\right)$, urinary $\alpha 1$-microglobulin $(4.24 \pm 4.03 \mu \mathrm{g} / \mathrm{gCr}$, $\left.6.30 \pm 5.12 \mu \mathrm{g} / \mathrm{gCr}, 17.83 \pm 18.08 \mu \mathrm{g} / \mathrm{gCr} ; P=8.84 \times 10^{-9}\right)$, and urinary angiotensinogen $(6.8 \pm 11.6 \mu \mathrm{g} / \mathrm{gCr}, 8.5 \pm 9.9 \mu \mathrm{g} / \mathrm{gCr}$, $\left.73.3 \pm 95.2 \mu \mathrm{g} / \mathrm{gCr} ; P=2.88 \times 10^{-4}\right)$.

By simple regression analyses of these parameters, urinary angiotensinogen levels significantly and positively correlated with ACR $\left(r=0.376, P=3.84 \times 10^{-4}\right)$ and urinary $\alpha 1$-microglobulin $\left(r=0.734, P=1.32 \times 10^{-15}\right)$, while they significantly and negatively correlated with eGFR $(r=-0.350$, $\left.P=1.02 \times 10^{-3}\right)$ and HDL-C $(r=-0.216, P=0.049)$ (Table 2 and Figure 1). We next investigated the correlations of urinary angiotensinogen, ACR, and urinary $\alpha 1$-microglobulin in various albuminuria stages. At all three albuminuria stages, urinary angiotensinogen levels did not correlate with ACR; however, urinary angiotensinogen levels significantly and highly correlated with $\alpha 1$-microglobulin at the normoalbuminuria stage $\left(r=0.840, P=1.40 \times 10^{-10}\right)$
Table 2 Simple correlation of urinary angiotensinogen with various clinical parameters in patients with type 2 diabetes $(\mathrm{n}=85)$

\begin{tabular}{|c|c|}
\hline & Angiotensinogen $(\mu \mathrm{g} / \mathrm{gCr})$ \\
\hline Age (years) & $r=-0.040, P=0.713$ \\
\hline BMI $\left(\mathrm{kg} / \mathrm{m}^{2}\right)$ & $r=-0.086, P=0.431$ \\
\hline $\mathrm{SBP}(\mathrm{mmHg})$ & $r=-0.033, P=0.764$ \\
\hline $\mathrm{DBP}(\mathrm{mmHg})$ & $r=-0.173, P=0.113$ \\
\hline $\mathrm{HbA}_{\mathrm{Ic}}(\%)$ & $r=-0.039, P=0.726$ \\
\hline Total protein $(g / L)$ & $r=-0.107, P=0.338$ \\
\hline Albumin $(g / L)$ & $r=-0.165, P=0.136$ \\
\hline $\mathrm{Cr}(\mu \mathrm{mol} / \mathrm{L})$ & $r=0.243, P=0.025^{*}$ \\
\hline $\mathrm{UN}(\mu \mathrm{mol} / \mathrm{L})$ & $r=0.362, P=0.001 * *$ \\
\hline Uric acid $(\mu \mathrm{mol} / \mathrm{L})$ & $r=0.08 \mathrm{I}, P=0.462$ \\
\hline T-Cho (mmol/L) & $r=-0.109, P=0.325$ \\
\hline TG (mmol/L) & $r=0.012, P=0.911$ \\
\hline HDL-C (mmol/L) & $r=-0.216, P=0.049 *$ \\
\hline LDL-C (mmol/L) & $r=-0.051, P=0.646$ \\
\hline eGFR (mL/min) & $r=-0.350, P=1.02 \times 10^{-3 * *}$ \\
\hline $\mathrm{ACR}(\mathrm{mg} / \mathrm{gCr})$ & $r=0.376, P=3.84 \times 10^{-4 * *}$ \\
\hline$\alpha \mathrm{I}$-microglobulin $(\mu \mathrm{g} / \mathrm{gCr})$ & $r=0.734, P=1.32 \times 10^{-15 * *}$ \\
\hline
\end{tabular}

Notes: $* P<0.05 ; * * P<0.01$. Spearman correlation coefficients are used.

Abbreviations: $A C R$, albumin/creatinine ratio; BMI, body mass index; $\mathrm{Cr}$, serum creatinine; DPB, diastolic blood pressure; eGFR, estimated glomerular filtration ratio; $\mathrm{HbA}_{\mathrm{Ic}}$, hemoglobin $\mathrm{A}_{\mathrm{Ic}}$; HDL-C, HDL cholesterol; LDL-C, LDL cholesterol; SBP, systolic blood pressure; T-Cho, total cholesterol; TG, triglyceride; UN, serum urea nitrogen. 

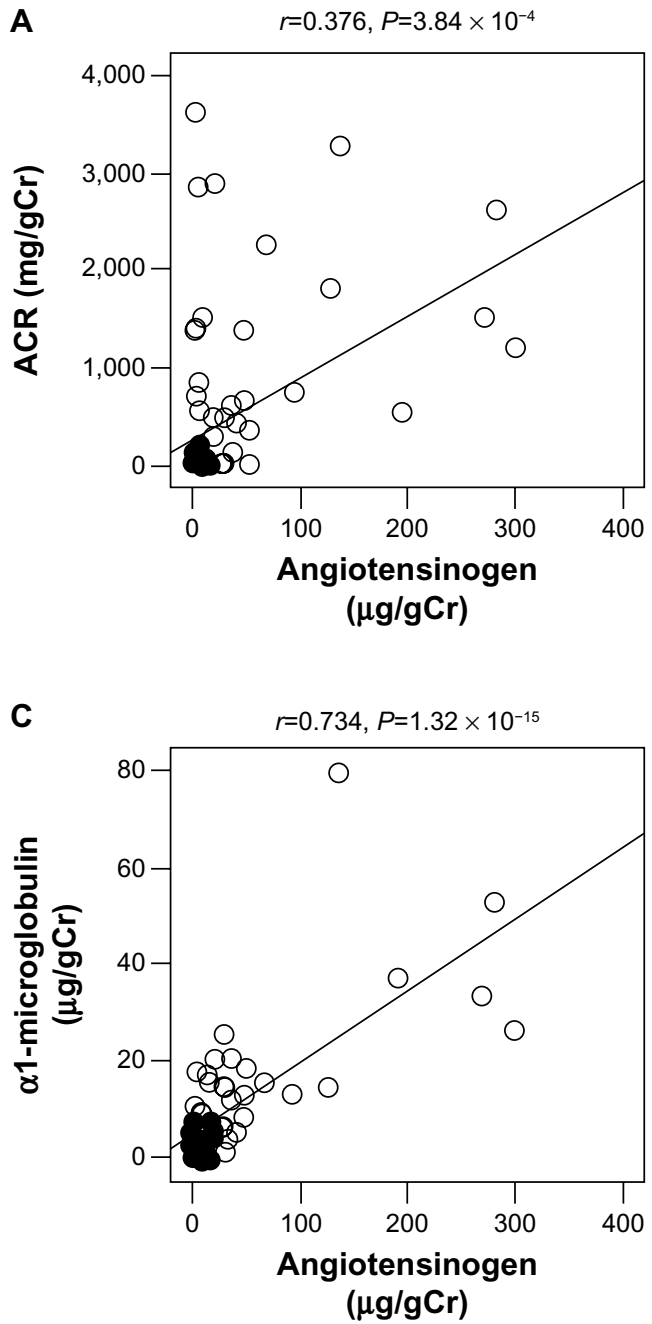
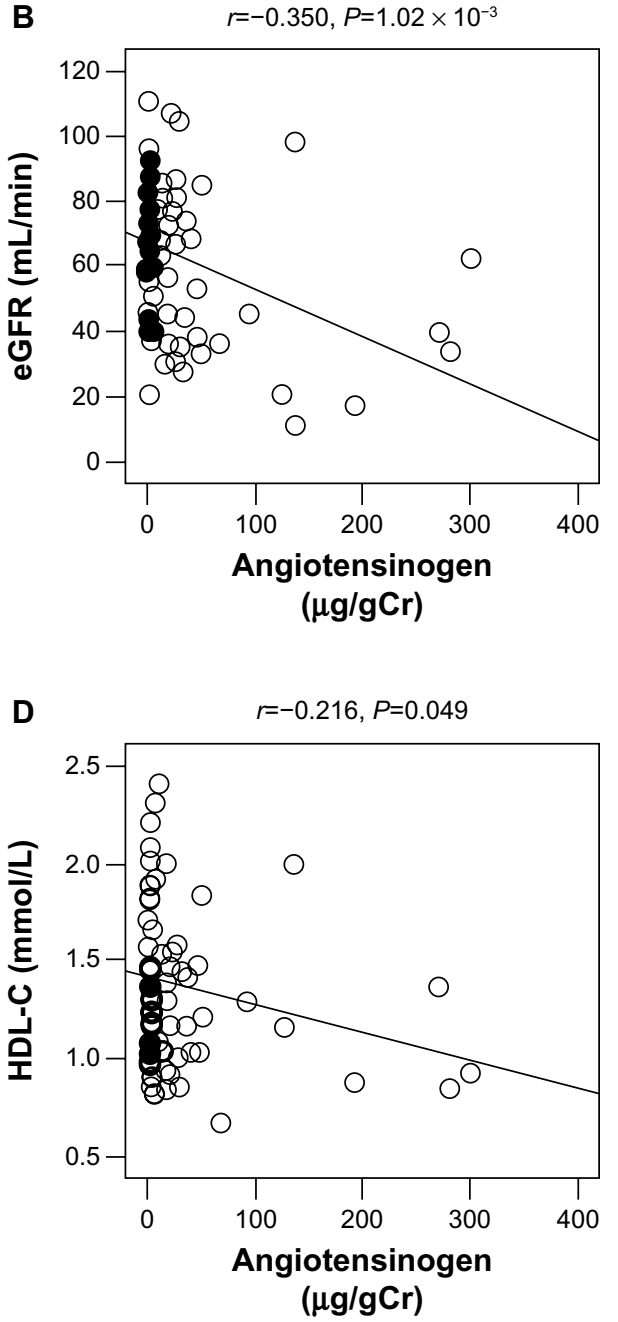

Figure I Simple correlation of urinary excretion of angiotensinogen with urinary ACR, eGFR, urinary $\alpha$ I-microglobulin, and HDL-C in patients with diabetic nephropathy ( $n=85$ ). A, urinary ACR; B, eGFR; C, urinary $\alpha \mathrm{I}$-microglobulin; and D, HDL-C.

Note: Spearman correlation coefficients are used.

Abbreviations: ACR, albumin/creatinine ratio; eGFR, estimated glomerular filtration ratio; HDL-C, high-density lipoprotein cholesterol.

(Figure 2). By multiple regression analysis including all parameters (eGFR, ACR, and urinary $\alpha 1$-microglobulin) as independent variables, only urinary $\alpha 1$-microglobulin was a significant independent variable (Table 3, Model 1). Furthermore, in stepwise multiple regression analysis, only urinary $\alpha 1$-microglobulin was employed as an independent variable (Table 3, Model 2).

\section{Urinary angiotensinogen}

\section{and $\alpha \mathrm{I}$-microglobulin levels unaltered in RAS inhibitors $(+)$ and $(-)$ groups}

We next compared various clinical parameters in the RAS inhibitors (+) and (-) groups. In RAS inhibitors (+), ACR was significantly higher compared with the RAS inhibitors (-) group $(368.2 \pm 863.8$ versus $489.8 \pm 779.8 \mathrm{mg} / \mathrm{gCr}$, $P=0.006)$. In contrast, there were no significant differences in urinary $\alpha 1$-microglobulin and angiotensinogen between the two groups (Figure 3). In clinical practice, type 2 diabetes patients with higher ACR seem to be preferentially treated with ARB or ACEI. Since urinary $\alpha 1$-microglobulin and angiotensinogen levels were not significantly higher in the RAS inhibitors (+) group, tubular damage and subsequent intrarenal RAS activation may be ameliorated by the administration of ARB or ACEI in RAS inhibitors (+) group.

\section{Discussion}

Proximal tubular angiotensinogen, collecting duct renin, and tubular angiotensin II type 1 receptors are positively augmented by intrarenal angiotensin (Ang) II. ${ }^{4}$ The infusion of ${ }^{125}$ I-Ang II into pigs demonstrated that steady-state concentrations of ${ }^{125}$ I-Ang II in cortical and medullary tissue were fourfold and twofold higher than arterial plasma and the tissue 
A

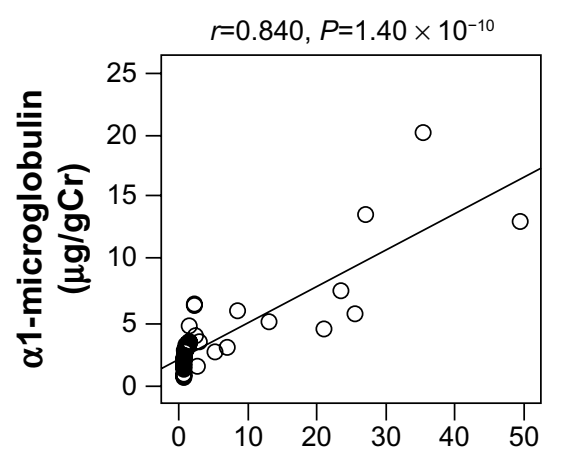

Angiotensinogen $(\mu \mathrm{g} / \mathrm{gCr})$

C

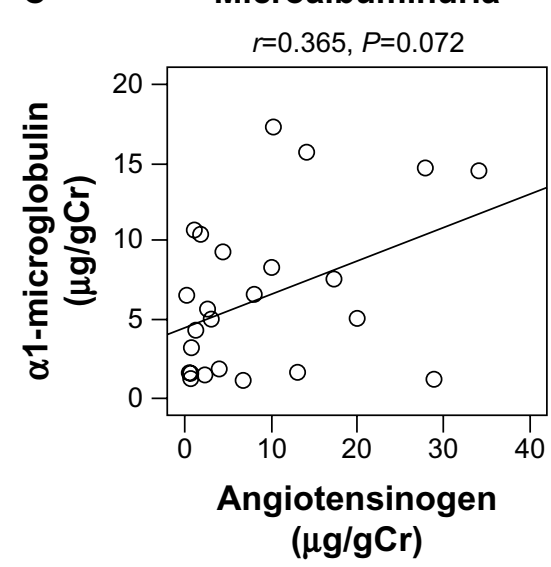

E

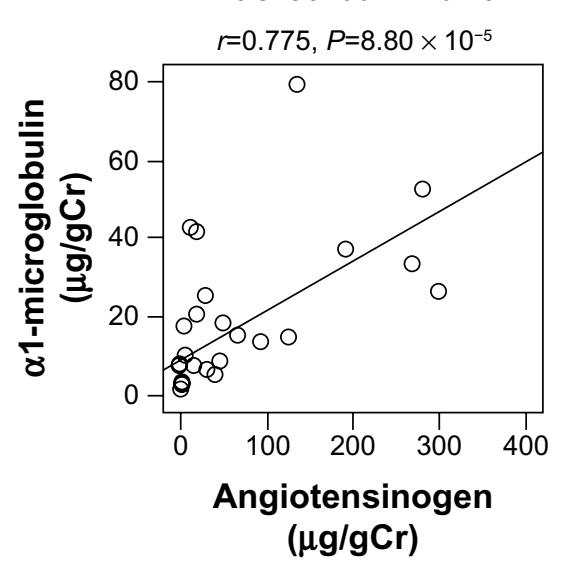

\section{B Normoalbuminuria}

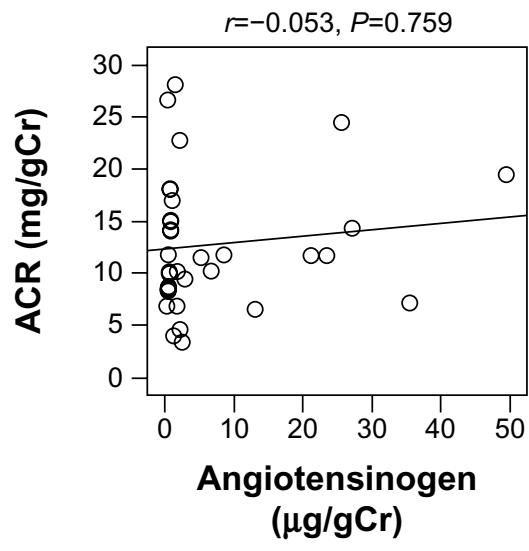

D Microalbuminuria

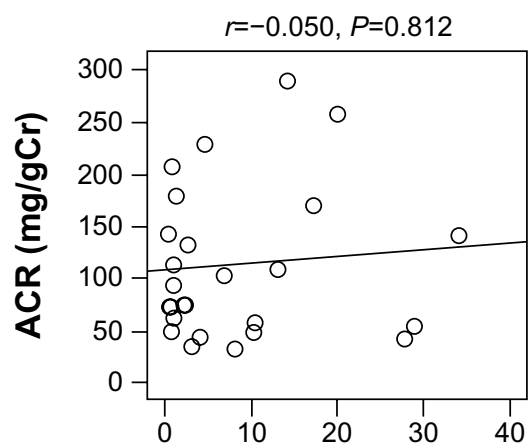

Angiotensinogen

$(\mu \mathrm{g} / \mathrm{gCr})$
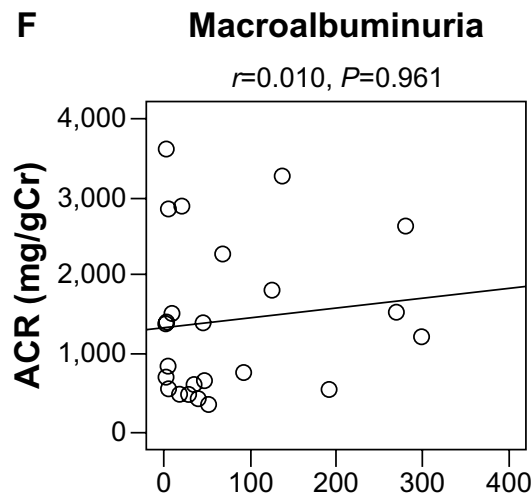

Angiotensinogen

$(\mu \mathrm{g} / \mathrm{gCr})$

Figure 2 Simple correlation of urinary excretion of angiotensinogen with urinary ACR and urinary $\alpha \mathrm{I}$-microglobulin in type 2 diabetes patients $(\mathrm{n}=85)$ in the normo- $(\mathrm{n}=36)$, micro- $(n=25)$, and macroalbuminuric $(n=24)$ stages.

Note: Spearman correlation coefficients are used. A, C and E, urinary ACR. B, D, and F, urinary $\alpha$ I-microglobulin. A and B, normoalubuminuria. C and D, microalbuminuria. $\mathbf{E}$ and $\mathbf{F}$, macroalbuminuria.

Abbreviation: ACR, albumin/creatinine ratio.

concentrations of endogenous Ang II were 100 and 60 times higher than arterial plasma. ${ }^{5}$ Thus, it is suggested that most renal Ang II type 1 receptors are exposed to locally generated Ang II rather than Ang II from circulation. In rodent models, the urinary excretion of angiotensinogen in streptozotocin- induced diabetic mice 3 days after the induction of diabetes was significantly higher $(349.6 \pm 89.1 \mu \mathrm{g} /$ day $)$ than control mice $(15.9 \pm 2.2 \mu \mathrm{g} /$ day $)$ and the authors demonstrated the upregulation of angiotensinogen messenger ribonucleic acid (mRNA) and protein expression in the mouse kidneys. ${ }^{6}$ The 
Table 3 Multiple linear regression analysis using urinary angiotensinogen as a dependent variable in patients with type 2 diabetes $(n=85)$

\begin{tabular}{|c|c|c|c|c|c|c|c|}
\hline \multirow[t]{2}{*}{$\begin{array}{l}\text { Dependent } \\
\text { variable }\end{array}$} & \multirow[t]{2}{*}{$\begin{array}{l}\text { Independent } \\
\text { variable }\end{array}$} & \multicolumn{2}{|c|}{$\begin{array}{l}\text { Unstandardized } \\
\text { coefficient }\end{array}$} & \multirow{2}{*}{$\begin{array}{l}\text { Standardized } \\
\text { coefficient } \\
\text { Beta }\end{array}$} & \multirow[t]{2}{*}{ t-value } & \multirow[t]{2}{*}{$P$-value } & \multirow[t]{2}{*}{ Adjusted $R^{2}$} \\
\hline & & B & Standard error & & & & \\
\hline Model I & $\mathrm{ACR}(\mathrm{mg} / \mathrm{gCr})$ & -0.001 & 0.007 & 0.014 & 0.142 & 0.888 & 0.519 \\
\hline Urinary & eGFR (mL/min) & 0.022 & 0.246 & 0.009 & 0.091 & 0.928 & \\
\hline $\begin{array}{l}\text { angiotensinogen } \\
(\mu \mathrm{g} / \mathrm{gCr})\end{array}$ & $\begin{array}{l}\text { Urinary } \alpha \mathrm{I}- \\
\text { microglobulin }(\mu g / g C r)\end{array}$ & 3.647 & 0.498 & 0.728 & 7.324 & $1.58 \times 10^{-10 * *}$ & \\
\hline $\begin{array}{l}\text { Model } 2 \\
\text { Urinary } \\
\text { angiotensinogen } \\
(\mu g / g C r)\end{array}$ & $\begin{array}{l}\text { Urinary } \alpha \mathrm{I}- \\
\text { microglobulin }(\mu \mathrm{g} / \mathrm{gCr})\end{array}$ & 3.668 & 0.374 & 0.732 & 9.800 & $1.64 \times 10^{-15 * *}$ & 0.531 \\
\hline
\end{tabular}

Notes: Estimated eGFR (mL/min), ACR ( $\mathrm{mg} / \mathrm{gCr})$, and $\alpha$ I-microglobulin $(\mu \mathrm{g} / \mathrm{gCr})$ are used as independent variables in multiple linear regression analysis. In Model I, all parameters are included; stepwise multiple linear regression analysis is performed in Model $2 . * * P<0.01$.

Abbreviations: ACR, albumin/creatinine ratio; eGFR, estimated glomerular filtration ratio.

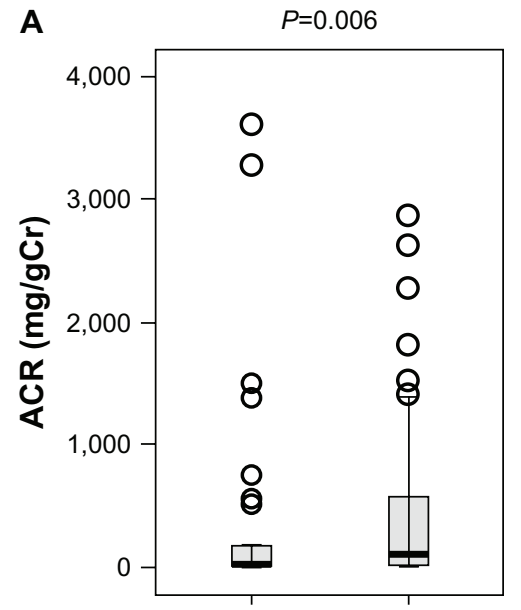

$(-) \quad(+)$

RAS inhibitors

C

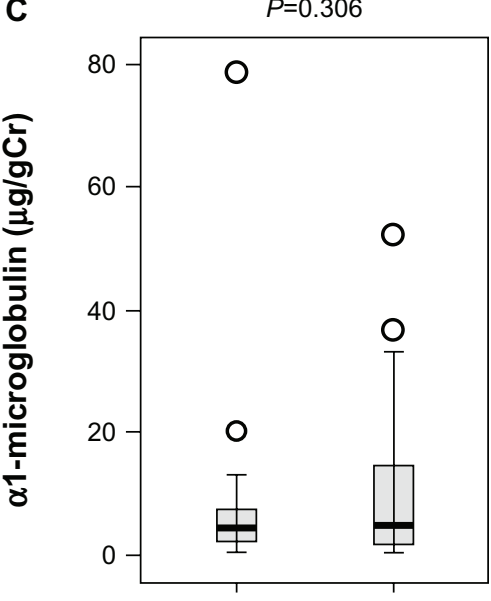

$(-)$

$(+)$

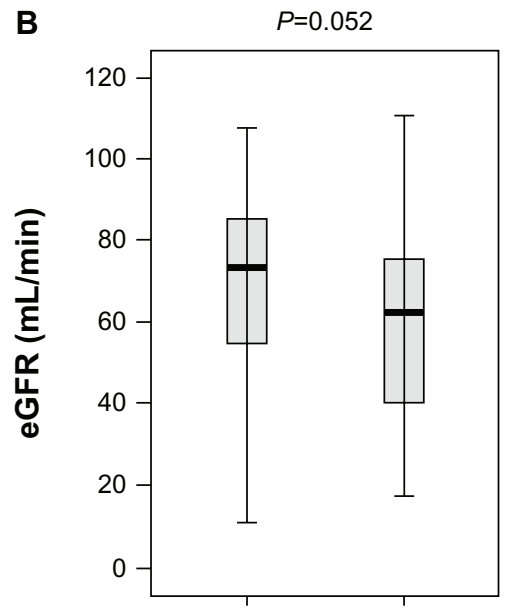

$(-) \quad(+)$

RAS inhibitors

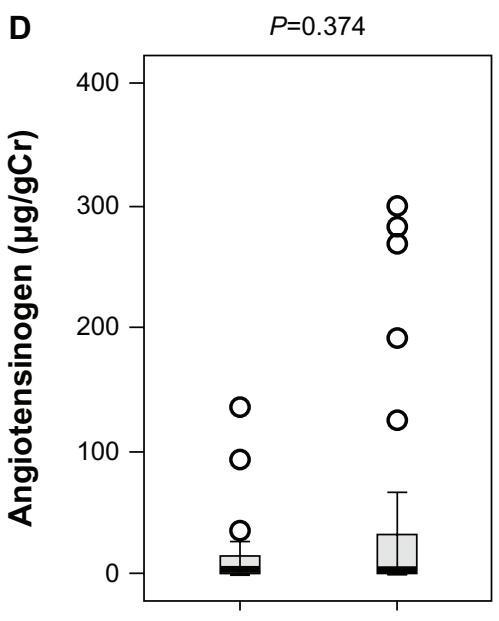

$(-) \quad(+)$

Figure 3 Urinary ACR, eGFR, urinary excretion of $\alpha$ I-microglobulin, and urinary excretion of angiotensinogen in patients with various stages of diabetic nephropathy ( $\mathrm{n}=85$ ). Notes: Urinary levels of albumin, $\alpha$ I-microglobulin, angiotensinogen, and eGFR in RAS inhibitors $(-)$ and RAS inhibitors (+) groups are compared by Mann-Whitney $U$. A, urinary ACR. B, eGFR. C, urinary excretion of $\alpha$ I-microglobulin. D, urinary excretion of angiotensinogen.

Abbreviations: ACR, albumin/creatinine ratio; eGFR, estimated glomerular filtration ratio; RAS, renin-angiotensin system. 
data suggested that urinary excretion of angiotensinogen is a biomarker for the activation of RAS in the kidney under diabetic states. In humans, plasma angiotensinogen reaches urine via glomerular filtration, like albumin, and the normal urinary angiotensinogen levels in humans is $\sim 0.2 \mathrm{pmol} / \mathrm{mL}$, versus $\sim 1,200 \mathrm{pmol} / \mathrm{mL}$ in plasma. Thus, the urinary angiotensinogen levels range from $0.01 \%$ to $0.1 \%$ of the plasma levels in humans. In contrast, urinary angiotensinogen levels in rodents are much higher and range from $0.1-400 \mathrm{pmol} / \mathrm{mL}$, implying that the urinary angiotensinogen levels in rodents are sometimes higher than their plasma levels. ${ }^{1}$ Less than 100-fold higher urinary angiotensinogen levels in rodents suggested the concept that urinary angiotensinogen is exclusively plasma-derived in humans, whereas it reflects angiotensinogen release from renal tissues, possibly proximal tubules, in rodents. Since albumin is produced in the liver and urinary albumin is entirely derived from plasma, the comparison of urinary albumin and angiotensinogen would demonstrate to what degree urinary angiotensinogen is plasma derived in humans. In fact, several studies, ${ }^{2,7-9}$ demonstrated high correlation between urinary albumin and angiotensinogen without exception.

In the current investigation, we simultaneously measured $\mathrm{ACR}$, urinary $\alpha 1$-microglobulin, and urinary angiotensinogen levels in the patients with type 2 diabetes and various stages of diabetic nephropathy. Urinary angiotensinogen levels significantly and positively correlated with ACR ( $r=0.376$, $P=3.84 \times 10^{-4}$ ) as previously reported, and we also found further high correlation with urinary $\alpha 1$-microglobulin $\left(r=0.734, P=1.32 \times 10^{-15}\right)$. High correlation of urinary $\alpha 1$-microglobulin and angiotensinogen levels was also found both in microalbuminuria and microalbuminuria stages; however, ACR did not show significant correlation with urinary angiotensinogen at normo-, micro-, and macroalbuminuria stages. The high correlation between urinary $\alpha 1-$ microglobulin and angiotensinogen levels at the normoalbuminuric stage supported the concept that tubular damage promotes the intrarenal RAS activation and production of tubular angiotensinogen, since the normoalbuminuric patients would not be expected to have leakage of plasma angiotensinogen into urinary space.

Urinary $\alpha 1$-microglobulin is filtered freely through glomerular capillaries and reabsorbed by the proximal tubules. ${ }^{10}$ Thus, urinary $\alpha 1$-microglobulin is a marker for proximal tubule dysfunction, and increased levels of urinary $\alpha 1$-microglobulin have been reported in normoalbuminuric patients with type 1 diabetes ${ }^{11,12}$ and type 2 diabetes. ${ }^{10,13,14}$ The assessment of proximal tubule dysfunction in the course of diabetes by urinary $\alpha 1$-microglobulin allows the early diagnosis of diabetic nephropathy prior to the appearance of microalbuminuria, and also predicts the progression of diabetic nephropathy. Plasma angiotensinogen is filtered through glomerular capillaries, and urinary angiotensinogen is mainly derived from plasma. Subsequently, urinary angiotensinogen is largely removed via endocytotic uptake in tubules in a megalin-dependent manner. Endocytotic angiotensinogen is subsequently degraded and the contents of angiotensinogen in the proximal convoluted tubules highly correlated with plasma levels of angiotensinogen. ${ }^{15}$ Thus, previous studies also support the idea that urinary excretion of angiotensinogen reflects not only abnormalities of glomerular filtration barrier but also proximal tubular functions. It has been reported that urinary angiotensinogen levels increase before glomerular injuries in the patients ${ }^{16}$ as well as in rodents. ${ }^{6}$

Yamamoto et al demonstrated that administration of losartan reduced urinary and plasma angiotensinogen levels in the patients with chronic kidney disease. ${ }^{17}$ In hypertensive patients with preserved kidney function, RAS blockers decreased the urinary angiotensinogen, and the decrease was comparable to that in urinary albumin ${ }^{7}$. Furthermore, in immunoglobulin A nephropathy, treatment with valsartan also reduced urinary angiotensinogen. ${ }^{18,19}$ As in various kidney diseases, RAS inhibitors suppressed urinary angiotensinogen levels with type 2 diabetes. ${ }^{20}$ One can speculate that reduction of urinary angiotensinogen by RAS blockers is due to the amelioration of glomerular hyperfiltration and suppression of enhanced filtration of various proteins, including angiotensinogen, through glomerular capillaries. Although ACR was higher in the RAS inhibitors (+) group, urinary $\alpha 1-$ microglobulin and angiotensinogen were not significantly increased in the RAS inhibitors (+) group. Thus, we speculate that RAS inhibitors may ameliorate the tubular injuries and intrarenal RAS activation, which was reflected by the lack of significant increase in urinary $\alpha 1$-microglobulin and angiotensinogen levels.

\section{Conclusion}

In summary, we demonstrated the significant and positive correlation of urinary angiotensinogen levels with ACR and urinary $\alpha 1$-microglobulin, and the negative correlation with eGFR. In a multiple regression analysis including all parameters (eGFR, ACR and urinary $\alpha 1$-microglobulin) as independent variables, only urinary $\alpha 1$-microglobulin was a significant independent variable. The current cross-sectional clinical study revealed that urinary angiotensinogen is a marker 
for tubular injuries of the early stage of diabetic nephropathy in patients with type 2 diabetes. Since the current study was a cross-sectional clinical investigation, the significance of urinary angiotensinogen for predicting long-term course of diabetic nephropathy is still unknown. In future studies, the significance of urinary angiotensinogen in predicting the progression of diabetic nephropathy needs to be demonstrated.

\section{Acknowledgments}

This work was supported by JSPS Grant-in-Aid for Scientific Research, Grants 23390241 and 25126716, and by the Health Labour Sciences Research Grant, Japan. KI, TT, and JW designed and performed most of the experiments. JE, AN, ST, KM, DO, TT, and AK recruited the patients. All authors contributed to conception and design, acquisition of data, or analysis and interpretation of data. In addition, all authors drafted the article, revised it critically for important intellectual content and gave final approval of the version to be published.

\section{Disclosure}

JW is a consultant for Boehringer Ingelheim, receives speaker honoraria from Novartis. HM is a consultant for Teijin, AbbVie and Astellas, receives speaker honoraria from Astellas, MSD, Takeda, and Tanabe Mitsubishi, and receives grant support from Astellas, Daiichi Sankyo, Dainippon Sumitomo, MSD, Novo Nodisk and Takeda. DO and AN belong to the Department of Diabetic Nephropathy, which is funded by Boehringer Ingelheim. The authors report no conflicts of interest in this work.

\section{References}

1. Roksnoer LC, Verdonk K, van den Meiracker AH, Hoorn EJ, Zietse R, Danser AH. Urinary markers of intrarenal renin-angiotensin system activity in vivo. Curr Hypertens Rep. 2013;15(2):81-88.

2. Sawaguchi M, Araki SI, Kobori H, et al. Association between urinary angiotensinogen levels and renal and cardiovascular prognoses in patients with type 2 diabetes mellitus. J Diabetes Investig. 2012;3(3): 318-324.

3. Inoue K, Wada J, Eguchi J, et al. Urinary Fetuin-A is a novel marker for diabetic nephropathy in type 2 diabetes identified by lectin microarray. PLOS ONE. In press.

4. Kobori H, Nangaku M, Navar LG, Nishiyama A. The intrarenal reninangiotensin system: from physiology to the pathobiology of hypertension and kidney disease. Pharmacol Rev. 2007;59(3):251-287.
5. van Kats JP, Schalekamp MA, Verdouw PD, Duncker DJ, Danser AH. Intrarenal angiotensin II: interstitial and cellular levels and site of production. Kidney Int. 2001;60(6):2311-2317.

6. Kamiyama M, Zsombok A, Kobori H. Urinary angiotensinogen as a novel early biomarker of intrarenal renin-angiotensin system activation in experimental type 1 diabetes. $J$ Pharmacol Sci. 2012;119(4):314-323.

7. Kobori $\mathrm{H}$, Alper AB, Shenava R, et al. Urinary angiotensinogen as a novel biomarker of the intrarenal renin-angiotensin system status in hypertensive patients. Hypertension. 2009;53(2):344-350.

8. Mills KT, Kobori H, Hamm LL, et al. Increased urinary excretion of angiotensinogen is associated with risk of chronic kidney disease. Nephrol Dial Transplant. 2012;27(8):3176-3181.

9. van den Heuvel M, Batenburg WW, Jainandunsing S, et al. Urinary renin, but not angiotensinogen or aldosterone, reflects the renal reninangiotensin-aldosterone system activity and the efficacy of reninangiotensin-aldosterone system blockade in the kidney. J Hypertens. 2011;29(11):2147-2155.

10. Hong CY, Hughes K, Chia KS, Ng V, Ling SL. Urinary alpha1microglobulin as a marker of nephropathy in type 2 diabetic Asian subjects in Singapore. Diabetes Care. 2003;26(2):338-342.

11. Korpinen E, Teppo AM, Hukkanen L, Akerblom HK, Grönhagen-Riska C, Vaarala O. Urinary transforming growth factor-betal and alpha1microglobulin in children and adolescents with type 1 diabetes. Diabetes Care. 2000;23(5):664-668.

12. Pfleiderer S, Zimmerhackl LB, Kinne R, Manz F, Schuler G, Brandis M. Renal proximal and distal tubular function is attenuated in diabetes mellitus type 1 as determined by the renal excretion of alpha 1-microglobulin and Tamm-Horsfall protein. Clin Investig. 1993;71(12):972-977.

13. Petrica L, Petrica M, Vlad A, et al. Nephro- and neuroprotective effects of rosiglitazone versus glimepiride in normoalbuminuric patients with type 2 diabetes mellitus: a randomized controlled trial. Wien Klin Wochenschr. 2009;121(23-24):765-775.

14. Petrica L, Petrica M, Vlad A, et al. Proximal tubule dysfunction is dissociated from endothelial dysfunction in normoalbuminuric patients with type 2 diabetes mellitus: a cross-sectional study. Nephron Clin Pract. 2011;118(2):c155-c164.

15. Richoux JP, Cordonnier JL, Bouhnik J, et al. Immunocytochemical localization of angiotensinogen in rat liver and kidney. Cell Tissue Res. 1983;233(2):439-451.

16. Saito T, Urushihara M, Kotani Y, Kagami S, Kobori H. Increased urinary angiotensinogen is precedent to increased urinary albumin in patients with type 1 diabetes. Am J Med Sci. 2009;338(6):478-480.

17. Yamamoto T, Nakagawa T, Suzuki H, et al. Urinary angiotensinogen as a marker of intrarenal angiotensin II activity associated with deterioration of renal function in patients with chronic kidney disease. $J$ Am Soc Nephrol. 2007;18(5):1558-1565.

18. Nishiyama A, KonishiY, Ohashi N, et al. Urinary angiotensinogen reflects the activity of intrarenal renin-angiotensin system in patients with IgA nephropathy. Nephrol Dial Transplant. 2011;26(1):170-177.

19. Urushihara M, Kondo S, Kagami S, Kobori H. Urinary angiotensinogen accurately reflects intrarenal Renin-angiotensin system activity. Am J Nephrol. 2010;31(4):318-325.

20. Ogawa S, Kobori H, Ohashi N, et al. Angiotensin II type 1 receptor blockers reduce urinary angiotensinogen excretion and the levels of urinary markers of oxidative stress and inflammation in patients with type 2 diabetic nephropathy. Biomark Insights. 2009;4:97-102.

\section{Publish your work in this journal}

The International Journal of Nephrology and Renovascular Disease is an international, peer-reviewed open-access journal focusing on the pathophysiology of the kidney and vascular supply. Epidemiology, screening, diagnosis, and treatment interventions are covered as well as basic science, biochemical and immunological studies. The journal welcomes original research, clinical studies, reviews \& evaluations, expert opinion and commentary, case reports and extended reports. The manuscript management system is completely online and includes a very quick and fair peerreview system, which is all easy to use. Visit http://www.dovepress.com/ testimonials.php to read real quotes from published authors. 